Научная статья

УДК 379.85

DOI https://doi.org/10.24866/VVSU/2073-3984/2021-4/072-084

В. Г. Ден ${ }^{1}$

А. В. Суходоева ${ }^{2}$

Владивостокский государственный университет экономики и сервиса

Владивосток. Россия

\title{
Основы проектирования туристских местностей в аспекте развития экологического туризма (на примере обустройства туристского маршрута «Гора Ливадийская» в Приморском крае)
}

\begin{abstract}
Аннотация. Статья посвящена исследованию особенностей проектирования туристских местностей с точки зрения развития экотуризма. Учитывая высокую ценность природной территории горы Ливадийской, популяризацию знаний об окружающей среде, пропаганду идей рационального природопользования и одновременное увеличение потребности современного туриста в «экологически чистом» отдыхе, выбранную тему можно считать актуальной. Целью исследования является разработка проекта обустройства туристского маршрута «Гора Ливадийская» в Приморском крае. В основе исследования лежит методика проектирования туристских местностей с использованием методов актуализации, системного анализа, статистического анализа и моделирования. В работе также приведен расчет максимальной нагрузки на экологический маршрут с учетом протяженности, продолжительности прохождения и максимального количества человек. Рассмотрены теоретические подходы к определению термина «экологический туризм», аспекты планирования туристских территорий, а также сделан вывод об актуальности развития туризма на особо охраняемых природных территориях. Практическая значимость работы заключается в разработке проекта обустройства экомаршрута на территории строящегося парка «Южно-Приморский». Разработанные проектные решения могут быть использованы в работе по благоустройству, строительству и реконструкции туристских местностей.
\end{abstract}

Ключевые слова: экологический туризм, планирование туристских территорий, особо охраняемые природные территории, обустройство маршрута, концепция устойчивого развития туризма, экотуристский маршрут.

1 Ден Валерия Гихоевна - ассистент кафедры туризма и экологии. ORCID: https://orcid.org/0000-0002-5872-6723; e-mail: denlero4ka96@ mail.ru

2 Суходоева Александра Владимировна - бакалавр 3-го курса кафедры туризма и экологии; e-mail: suhodoevaalexandra@yandex.ru

72 
V.G. Den

A.V. Suhodoeva

Vladivostok State University of Economics and Service

Vladivostok. Russia

\title{
Fundamentals for designing tourist locations in the aspect of development of ecological tourism (on the example of the arrangement of the turitian route of mountain Livadiyskaya in Primorsky krai)
}

\begin{abstract}
Abstact. The article is devoted to the study of the design features of tourist areas from the point of view of the development of ecotourism. Considering the high value of the natural area of Mount Livadiyskaya, the popularization of environmental knowledge, the promotion of the ideas of rational use of natural resources and the simultaneous increase in the modern tourist's need for "environmentally friendly" recreation, the chosen topic can be considered relevant. The aim of the study is to develop a project for arranging a tourist route for Mount Livadiyskaya in the Primorsky Territory. The research is based on the methodology of designing tourist areas using methods of actualization, system analysis, statistical analysis and modeling. The work also provides a calculation of the maximum load on the ecological route, taking into account the length, duration of the passage and the maximum number of people. Theoretical approaches to the definition of the term "ecological tourism", aspects of planning tourist areas are considered, and a conclusion is made about the relevance of tourism development in specially protected natural areas. The practical significance of the work lies in the development of a project for the arrangement of an eco-route on the territory of the Yuzhno-Primorsky park under construction. The developed design solutions can be used in the improvement, construction and reconstruction of tourist areas.
\end{abstract}

Keywords: ecological tourism, planning of tourist areas, specially protected natural areas, arrangement of the route, the concept of sustainable tourism development, ecotourism route.

\section{Введение}

Экологический туризм на сегодняшний день является одним из самых активно развивающихся видов туризма. Интерес к экотуризму обусловлен стремлением к минимизации изменений окружающей среды. Необходимо отметить, что вопросы, касающиеся экологического туризма в современном мире, стоят наиболее остро, в особенности из-за иррациональности использования туристских ресурсов в стране.

Пресыщение массовым туристским продуктом привело к возникновению потребности в нестандартном отдыхе, что и стало причиной возникновения множества альтернатив, в том числе экологической направленности. Так, например, такие термины, как мягкий, зеленый, устойчивый, сельский, экологический, характеризующие туристскую отрасль, имеют различные трактовки, но во многом схожи по значению [1].

Происхождение всех форм туризма природно-ориентированной направленности обусловлено развитием современного общества, а также возникшими тенденциями к бережному отношению к окружающей среде, ростом экологического соз- 
нания человека и беспокойством за сохранность планеты и биологического разнообразия.

Согласно определению, принятому Всемирной туристской организацией, экологический туризм включает в себя «все формы природного туризма, при которых основной мотивацией туристов является наблюдение и приобщение к природе» [2].

В современных источниках наиболее часто встречается определение А.В. Бабкина, который характеризует экологический туризм как природный, как «относительно неискаженную или незагрязненную область с уникальными природными объектами», где в первую очередь организуют поездки с ограниченным количеством участников в природные зоны, «представляющие культурный интерес, с целью реализации различных проектов охраны и рационального использования природных ресурсов» [3].

Популярны также определения различных сообществ, ассоциаций, министерств и союзов развития экологического туризма (табл. 1) [4-10].

Таблийа 1

Научные подходы к определению термина «экологический туризм»

\begin{tabular}{|l|l|}
\hline \multicolumn{1}{|c|}{ Источник } & \multicolumn{1}{c|}{ Определение } \\
\hline $\begin{array}{l}\text { Национальная стратегия } \\
\text { развития экотуризма (Авст- } \\
\text { ралия) }\end{array}$ & $\begin{array}{l}\text { Природно-ориентированный туризм, который включает про- } \\
\text { граммы экообразования и просвещения и осуществляется в со- } \\
\text { ответствии с принципами экологической устойчивости }\end{array}$ \\
\hline $\begin{array}{l}\text { Международная ассоциация } \\
\text { экологического туризма }\end{array}$ & $\begin{array}{l}\text { Целенаправленные путешествия в природные территории с це- } \\
\text { льюдее глубокого понимания местной культуры и природной } \\
\text { ценность природных ресурсов и мотивацию к их сохранению } \\
\text { среди местных жителей }\end{array}$ \\
\hline $\begin{array}{l}\text { Федеральное министерство } \\
\text { по финансовому сотрудни- } \\
\text { честву и развитию Германии }\end{array}$ & $\begin{array}{l}\text { Вид туризма, целью которого является сведение к минимуму } \\
\text { мощи в финансировании особо охраняемых природных террито- } \\
\text { рий, формирование источников дохода для местного населения }\end{array}$ \\
\hline $\begin{array}{l}\text { Международный союз охра- } \\
\text { ны природы и природных } \\
\text { ресурсов }\end{array}$ & $\begin{array}{l}\text { Путешествие с ответственностью перед окружающей средой по } \\
\text { относительно ненарушенным природным территориям с целью } \\
\text { изуния и наслаждения природой и культурными достоприме- } \\
\text { чательностями, которое содействует охране природы, оказывает } \\
\text { «мягкое» воздействие на окружающую среду, обеспечивает ак- } \\
\text { тивное социально-экономическое участие местных жителей и } \\
\text { получение ими преимуществ от этой деятельности }\end{array}$ \\
\hline $\begin{array}{l}\text { Программа Всемирного бан- } \\
\text { ка по развитию экотуризма } \\
\text { на Байкале }\end{array}$ & $\begin{array}{l}\text { Любые формы туризма и деятельности на природе, которые } \\
\text { имеют главной задачей восприятие природы и ее красоты, по- } \\
\text { нимание значения окружающей среды, отдых и спортивный } \\
\text { туризм на лоне природы }\end{array}$ \\
\hline
\end{tabular}

Примечание: составлено автором по [4-10].

Все определения экологического туризма были даны в конце XX - начале XXI века и являются актуальными на сегодняшний день. Многообразие трактовок говорит о широте содержания и наличии различных форм деятельности 
В.Г. Ден, А.В. Суходоева. Основы проектирования туристских местностей...

внутри экотуризма. Каждое определение отражает отдельные аспекты и демонстрирует историческое развитие, цели и задачи отрасли.

Экологический туризм - это единственное направление в индустрии туризма, заинтересованное в сохранении своего главного ресурса - естественной природной среды или её отдельных компонентов (памятников природы, определённых видов животных или растений и т.д.), поэтому он основан на принципах минимизации негативного воздействия, усиления широкого охвата и повышения природоохранного, экологического и культурного сознания.

Стратегия развития туризма в Российской Федерации на период до 2035 года (утверждена распоряжением Правительства РФ от 20.09.2019 № 2129-p) [11] предполагает разработку отдельной концепции развития экотуризма в Российской Федерации на период до 2035 г., в которой будет обоснован переход к модели экологического туризма как комплексному направлению, обеспечивающему взаимосвязь туризма, культуры и экологии, а также будет уделено внимание организации регулируемого туризма на особо охраняемых природных территориях (ООПТ).

\section{Основная часть}

Территория Дальневосточного региона, в частности Приморский край, обладает рядом преимуществ, благодаря которым можно рассматривать въездной экологический туризм, в том числе на особо охраняемых природных территориях, в качестве одного из основных направлений развития региона.

На сегодняшний день уже активно внедряются формы регулируемого туризма на ООПТ Приморского края (ФГБУ «Земля леопарда», национальные парки «Удэгейская легенда» и «Бикин»).

Необходимо отметить, что режим особо охраняемых природных территорий допускает строительство (с учетом предельных параметров), реконструкцию объектов недвижимости (за исключением линейных объектов), при этом устанавливается жесткий режим использования участков в границах ООПТ, включая полный запрет на возведение на них объектов капитального строительства, непосредственно не связанных с использованием ООПТ, а также изменение функционального назначения участка [12].

Вследствие этого подход к проектированию, строительству и реконструкции на ООПТ с целью развития экотуристской инфраструктуры основан на концепции устойчивого развития (при котором удовлетворение потребностей настоящего времени не ухудшит способность будущих поколений удовлетворять свои).

В применении концепции устойчивого развития основным является прогнозирование возможных последствий техногенного вмешательства в среду (в социальном и экологическом аспектах), а также учет требований среды к проектным решениям, технологии строительства и правилам эксплуатации сооружений. При проектировании, строительстве и эксплуатации объектов экологической инфраструктуры необходимо соблюдать баланс между потребностями человека и возможностями окружающей среды [13].

Сущность планирования заключается в процессе подготовки, разработки, оформления и реализации бизнес-проекта посредством создания необходимых организационных условий, проведения исследований и расчетов, подготовки и 
оформления экономической, финансовой и другой необходимой документации по проекту [14].

Объекты инфраструктуры на ООПТ подразделяются на базовые и коммерческие (рис. 1) [15].

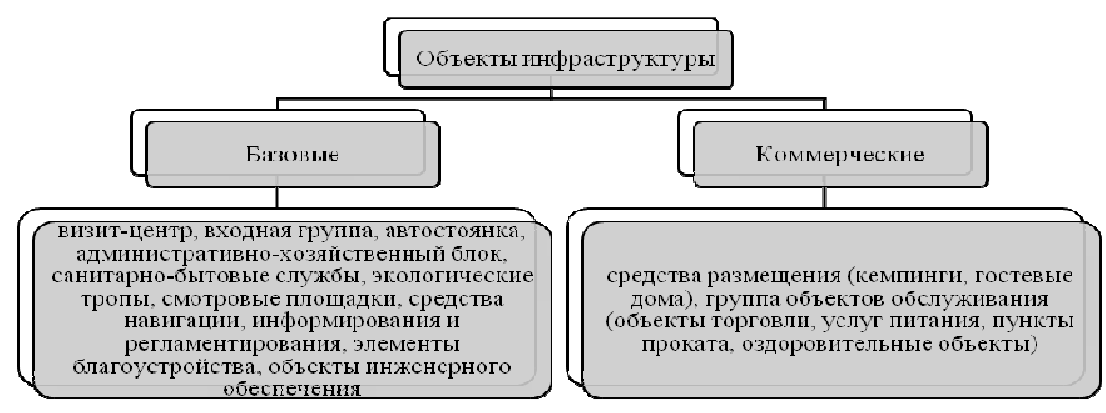

Рис. 1. Объекты инфраструктуры на ООПТ

Источник: составлено автором по [15].

Таким образом, в рамках проектирования особо охраняемых природных территорий в них можно включать базовые объекты (визит-центр, входную группу, автостоянку, административный и бытовой блоки, экологические тропы, смотровые площадки и т.п.) и коммерческие (средства размещения и различные объекты обслуживания).

В общем схему проектирования можно представить следующим образом (рис. 2) [13].

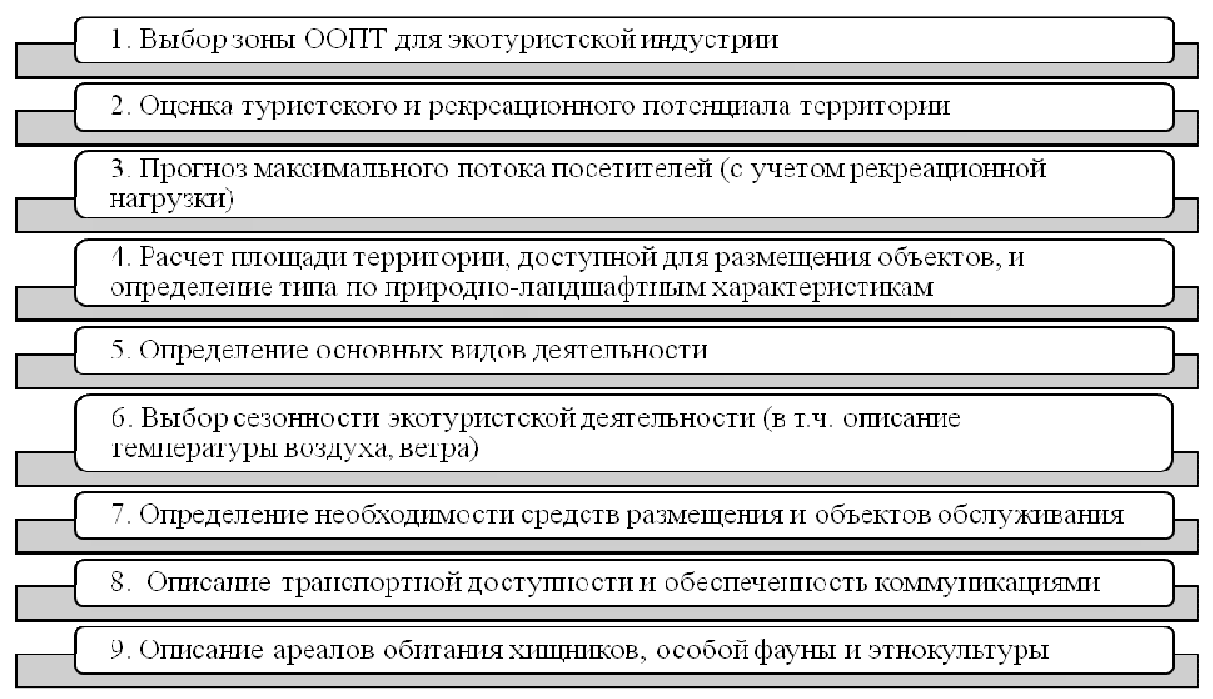

Рис. 2. Этапы проектирования ООПТ

Источник: составлено автором по [13]. 
Последовательное решение вопросов, указанных в схеме, позволит организовать деятельность и инфраструктуру на особо охраняемых территориях.

Проектирование туристской территории является сложным и многоаспектным процессом, включает в себя систему планомерно организованных экономических, технических, организационных и социальных мероприятий, направленных на достижение поставленной цели и согласованных по целям и ресурсам. В особенности важно учитывать специфику ООПТ, так как проектирование неразрывно связано с природными условиями, генеральным планом, диктующим характер общей пространственной концепции многофункционального парка, основой для которой служит взаимодействие элементов архитектуры и ландшафта.

Сегодня одним из важных проектов является концепция развития туризма на территории природного парка «Южно-Приморский». Территория парка площадью 19988 га состоит из трех обособленных участков, расположенных на территории Шкотовского, Партизанского муниципальных районов и Партизанского городского округа Приморского края, на каждом из которых есть природные, культурноисторические, социально-экономические рекреационные ресурсы.

Для развития экологического туризма на территории парка актуально разработать проект обустройства туристского маршрута «Гора Ливадийская» (до 1972 года - гора Пидан). Это одна из главенствующих высот южного Приморья (1332,6 м над уровнем моря); входит в состав Ливадийского хребта горной системы Сихотэ-Алиня.

Организация регулируемого рекреационного природопользования, использование в туристско-рекреационных целях природного объекта - горы Ливадийской, расположенной на территории национального парка, требует мер по его обустройству.

Гора Ливадийская находится в пределах зоны заказного режима по плану зонирования проектируемого парка «Южно-Приморский» [16], обеспечивающей сохранение природных объектов, на которых ограничивается хозяйственная деятельность и регламентируется рекреационная деятельность.

Основные услуги на маршруте представлены экскурсионным и индивидуальным посещением. Характеристика экотуристского маршрута «Гора Ливадийская» представлена в табл. 2.

Таблийа 2

Характеристика проекта развития экотуристского маршрута «Гора Ливадийская»

\begin{tabular}{|l|l|l|}
\hline \multicolumn{1}{|c|}{ Показатель } & \multicolumn{2}{|c|}{ Описание } \\
\hline Тип экскурсии & $\begin{array}{l}\text { Индивидуальное посеще- } \\
\text { ние экологической тропы } \\
\text { Ливадийской }\end{array}$ & $\begin{array}{l}\text { Экскурсионное обслуживание экологической } \\
\text { тропы Ливадийской }\end{array}$ \\
\hline $\begin{array}{l}\text { Эодержание } \\
\text { экскрсии }\end{array}$ & $\begin{array}{l}\text { Самостоятельный осмотр } \\
\text { достопримечательностей и } \\
\text { природных объектов }\end{array}$ & $\begin{array}{l}\text { Экскурсия в сопровождении гида- } \\
\text { экскурсовода с применением обучающей кон- } \\
\text { справку, инфорорая включает историческую современном состоя- } \\
\text { нии и развитии туризма }\end{array}$ \\
\hline
\end{tabular}


Окончание табл. 2

\begin{tabular}{|c|c|}
\hline Показатель & Описание \\
\hline Протяженность & 13,89 км \\
\hline $\begin{array}{l}\text { Длительность } \\
\text { прохождения }\end{array}$ & $5-7$ ч \\
\hline $\begin{array}{l}\text { Категория } \\
\text { сложности }\end{array}$ & Не категорийна \\
\hline $\begin{array}{l}\text { Категория по- } \\
\text { требителя }\end{array}$ & Доступна для туристов от 12 лет \\
\hline Сезонность & Круглогодичная \\
\hline $\begin{array}{l}\text { Оснащенность } \\
\text { тропы }\end{array}$ & Информационные стенды и указатели отсутствуют \\
\hline Территория & Проектируемый национальный парк «Южно-Приморский» \\
\hline $\begin{array}{l}\text { Потребность в } \\
\text { обустройстве }\end{array}$ & $\begin{array}{l}\text { Обустройство зоны парковки; } \\
\text { обустройство санитарно-бытовых зон (туалеты); } \\
\text { обустройство зон отдыха; } \\
\text { создание входной группы; } \\
\text { установка средств навигации, информирования и регламентирования; } \\
\text { обустройство маршрута; } \\
\text { посадка растений дальневосточной флоры }\end{array}$ \\
\hline
\end{tabular}

Примечание: составлено автором.

Основной объем финансовых вложений должен быть направлен на благоустройство территории, зонирование и составление эколого-образовательного содержания маршрута. Маршрут является сложным и нуждается в устройстве лестниц, деревянного полотна, видовых площадок, ограждений и поручней; возможно, на нем потребуется установить помосты или небольшие мосты.

При обустройстве тропы целесообразно использовать оставшиеся после санитарной очистки леса природные материалы, что повысит экономичность и экологичность проекта. Помимо этого необходимо благоустроить въезд и частично восстановить покрытие дороги.

Проект экотуристского маршрута предполагает оформление зон, представленных в табл. 3.

Так, на маршруте предполагаются входная, тематическая зоны и зона короткого отдыха.

Для обустройства маршрута, повышения эстетической и образовательной ценности целесообразно провести мероприятия, описанные в табл. 4. 


\section{Зоны экотуристского маршрута «Гора Ливадийская»}

\begin{tabular}{|c|c|c|}
\hline Входная зона & Тематическая зона & Зона отдыха \\
\hline $\begin{array}{l}\text { 1. Парковка для ограниченного количе- } \\
\text { ства автомобилей у подножия. } \\
\text { 2. Магазин плюс сувенирная лавка. } \\
\text { 3. Биотуалет. } \\
\text { 4. Информационная площадка. } \\
\text { 5. Стенды: } \\
\text { а) описание особенностей } \\
\text { окружающих природных ландшафтов; } \\
\text { б) схема маршрута с обозначением ви- } \\
\text { довых точек, информационных площа- } \\
\text { док, зон для отдыха; } \\
\text { в) правила поведения на маршруте }\end{array}$ & $\begin{array}{l}\text { 1. Информационная } \\
\text { площадка, посвящен- } \\
\text { ная особенностям Ли- } \\
\text { вадийского хребта. } \\
2 . \text { Обустройство видо- } \\
\text { вых точек с огражде- } \\
\text { ниями, скамьями и } \\
\text { урнами, установка } \\
\text { стендов с мифами и } \\
\text { легендами о горе Ли- } \\
\text { вадийской }\end{array}$ & $\begin{array}{l}\text { 1. Площадка для отдыха } \\
\text { на середине маршрута и } \\
\text { на вершине. } \\
\text { 2. Навесы. } \\
\text { 3. Скамейки и урны. } \\
\text { 4. Обустройство этой } \\
\text { зоны позволит снизить } \\
\text { деградацию почвенного } \\
\text { покрова, уменьшить за- } \\
\text { грязнение территории } \\
\text { мусором и сделать пре- } \\
\text { бывание посетителей } \\
\text { более комфортным }\end{array}$ \\
\hline
\end{tabular}

Примечание: составлено автором.

Таблица 4

Проект обустройства маршрута «Гора Ливадийская»

\begin{tabular}{|c|c|c|}
\hline № п/п & Вид работ & Описание \\
\hline 1 & Обустройство зоны парковки & $\begin{array}{l}\text { Для автомобилей и туристических автобусов } \\
\text { (ограниченное количество) }\end{array}$ \\
\hline 2 & $\begin{array}{l}\text { Обустройство санитарно-бытовых зон } \\
\text { (туалеты) }\end{array}$ & $\begin{array}{l}\text { Установка: } \\
\text { туалетов; } \\
\text { рукомойников }\end{array}$ \\
\hline 3 & Оснащение зон отдыха & $\begin{array}{l}\text { Установка: } \\
\text { скамеек; } \\
\text { навесов; } \\
\text { столов; } \\
\text { сувенирной продукции }\end{array}$ \\
\hline 4 & Создание входной группы & $\begin{array}{l}\text { Разработка дизайн-макета, его изготовление } \\
\text { и установка }\end{array}$ \\
\hline 5 & $\begin{array}{l}\text { Размещение стендов и табличек по } \\
\text { растениям }\end{array}$ & $\begin{array}{l}\text { Разработка дизайн-макетов; конструкция } \\
\text { стендов, их печать и установка }\end{array}$ \\
\hline 6 & Общее обустройство маршрута & $\begin{array}{l}\text { Установка: } \\
\text { - лестницы; } \\
\text { - видовых площадок; } \\
\text { - деревянного полотна; } \\
\text { - ограждений и поручней; } \\
\text { - мостов; } \\
\text { - указателей }\end{array}$ \\
\hline
\end{tabular}

Примечание: составлено автором. 
Проект включает в себя несколько мероприятий, в том числе обустройство зоны парковки, санитарно-бытовых зон (туалеты) и общее обустройство маршрута, а также создание входной группы и размещение стендов и указателей.

Примеры стилей средств навигации, информирования и регулирования представлены на рис. 3 .


Рис. 3. Примеры стилей средств навигации, информирования и регулирования

Источник: составлено автором.

Оформление плакатов, стендов и указателей может быть выполнено в различных стилистических вариантах: от включения мультипликационных эффектов до более серьезных и деловых.

Весь спектр услуг можно разделить на два основных направления: платные и бесплатные (табл. 5).

Таблица 5

Характеристика предоставляемых услуг

\begin{tabular}{|l|l|l|}
\hline \multicolumn{1}{|c|}{$\begin{array}{c}\text { Наименование } \\
\text { услуги }\end{array}$} & \multicolumn{1}{|c|}{ Характеристика } & \multicolumn{1}{|c|}{$\begin{array}{c}\text { Платно/ } \\
\text { бесплатно }\end{array}$} \\
\hline $\begin{array}{l}\text { Продажа сувенир- } \\
\text { ной продукции }\end{array}$ & $\begin{array}{l}\text { Возможность приобрести сувенирную продукцию } \\
\text { с отличительной символикой, относящейся к г. } \\
\text { Ливадийской }\end{array}$ & $\begin{array}{l}\text { Согласно прей- } \\
\text { скуранту цен }\end{array}$ \\
\hline $\begin{array}{l}\text { Продажа продо- } \\
\text { вольственных про- } \\
\text { дуктов }\end{array}$ & $\begin{array}{l}\text { Возможность приобрести легкие закуски, напитки, } \\
\text { предметы первой необходимости }\end{array}$ & $\begin{array}{l}\text { Согласно прей- } \\
\text { скуранту цен }\end{array}$ \\
\hline Санитарный узел & Пользование биотуалетом и умывальником & Бесплатно \\
\hline Зарядка телефона & Зарядка любого телефона при необходимости & Платно \\
\hline
\end{tabular}


В.Г. Ден, А.В. Суходоева. Основы проектирования туристских местностей...

Окончание табл. 5

\begin{tabular}{|l|l|l|}
\hline \multicolumn{1}{|c|}{$\begin{array}{c}\text { Наименование } \\
\text { услуги }\end{array}$} & \multicolumn{1}{|c|}{ Характеристика } & \multicolumn{1}{|c|}{$\begin{array}{c}\text { Платно/ } \\
\text { бесплатно }\end{array}$} \\
\hline Зона отдыха & $\begin{array}{l}\text { В нее входит расположение в беседках или на } \\
\text { лавочках }\end{array}$ & Бесплатно \\
\hline Услуги гида & $\begin{array}{l}\text { Предоставляются заранее по договоренности в } \\
\text { группах и индивидуально }\end{array}$ & Платно \\
\hline Входной билет & $\begin{array}{l}\text { Оплата входного билета производится на входе в } \\
\text { парк «Южн-Приморский»; дополнительно на гору } \\
\text { плата не взимается }\end{array}$ & Бесплатно \\
\hline
\end{tabular}

Примечание: составлено автором.

Исходя из данных таблицы видно, что маршрут будет предоставлять различные виды услуг, в том числе зарядку телефона, пользование зоной отдыха, продажу сувенирной и продовольственной продукции.

Расчет максимальной нагрузки на экологический маршрут «Гора Ливадийская» произведен с учетом протяженности, продолжительности прохождения, максимального количества человек в группе (табл. 6).

Таблица 6

Расчёт максимальной нагрузки на экологический маршрут

\begin{tabular}{|c|c|c|}
\hline Показатели & \multicolumn{2}{|c|}{ Значение } \\
\hline Длина маршрута экологической тропы & \multicolumn{2}{|l|}{3000 м } \\
\hline Направление потока посетителей & \multicolumn{2}{|l|}{1 маршрут } \\
\hline Время посещения экотропы, общее (с 9:00 до 18:00) & \multicolumn{2}{|l|}{9 ч } \\
\hline $\begin{array}{l}\text { Время посещения экотропы для младших школьников (с 11:00 до } \\
\text { 15:00) }\end{array}$ & \multicolumn{2}{|l|}{7 ч } \\
\hline Максимальный размер группы & \multicolumn{2}{|l|}{15 чел. } \\
\hline Минимальное расстояние между туристскими группами & \multicolumn{2}{|l|}{$750 \mathrm{M}$} \\
\hline Расчет & \multicolumn{2}{|l|}{ Ед. изм. } \\
\hline $\begin{array}{l}\text { При рекомендуемой дистанции между группами (18 промежут- } \\
\text { ков) в } 750 \text { м на тропе и при условии, что одному человеку нужен } \\
1 \text { м тропы, одновременно могут находиться } 19 \text { групп, для кото- } \\
\text { рых потребуется }\end{array}$ & $\begin{array}{l}19 \text { гр. } 15 \mathrm{~m}+ \\
18 \cdot 750 \mathrm{~m}= \\
13785\end{array}$ & $\begin{array}{l}\text { метров } \\
\text { тропы }\end{array}$ \\
\hline Маршрут открыт 9 ч в сутки, для подъема и спуска требуется 7 ч & $9: 7=1,28$ & $\begin{array}{l}\text { посеще- } \\
\text { ний/день }\end{array}$ \\
\hline Физически 19 групп используют 285 м тропы & $\begin{array}{l}285 \text { м тропы } \\
1 ч / \mathrm{M} \cdot 1,28 \\
\text { посеще- } \\
\text { ний/день }=365\end{array}$ & $\begin{array}{l}\text { чел./ } \\
\text { день }\end{array}$ \\
\hline
\end{tabular}

Примечание: составлено автором. 
Таким образом, максимальное количество человек на маршруте в день составляет 365 человек, что позволит сохранить местную природу.

Формирование маршрута «Гора Ливадийская» и дальнейшее развитие инфраструктуры парка в целом привлекут потоки туристов, будут способствовать созданию рабочих мест и повышению уровня социально-экономического развития муниципальных районов Приморского края и качества жизни их населения.

\section{Выводы и научная новизна}

Возрастающее значение проблем экологического характера в туристских дестинациях, увеличение целевой группы потребителей, рост усилий, прилагаемых для обеспечения устойчивого туризма на ООПТ, способствуют росту объема экотуристских поездок. Видовое разнообразие экологических туров говорит о популярности и востребованности экотуризма в современном мире. Россия с ее богатейшим культурным наследием и природно-ресурсным потенциалом, региональным разнообразием традиционных форм природопользования потенциально является одной из наиболее привлекательных стран для экологического туризма.

Отмечено, что проектирование туристских территорий является сложным и многоаспектным процессом; особенно важно учитывать специфику ООПТ, так как проектирование неразрывно связано с природными условиями.

Географическое положение Приморского края дает уникальный природноклиматический комплекс в совокупности с культурно-историческими ресурсами, что благоприятно влияет на развитие большинства видов туризма. Благодаря наличию на территории края ресурсов, в том числе системы природных комплексов, обширной сети особо охраняемых природных территорий, мягкого климата, приморских и таежных ландшафтов, животного и растительного мира, природных, исторических памятников культуры и природы, целесообразным видится развитие экологического туризма.

Научной новизной работы является уточнение понятия «экологический туризм». На основании комплексного исследования выявлен алгоритм проектирования особо охраняемых природных территорий. В качестве практической составляющей разработан экологический маршрут с характеристикой услуг, проектом общего обустройства, зонированием и стилевыми решениями для средств навигации, информирования и регулирования. Произведен расчет максимальной нагрузки на экологический маршрут. Разработанный в статье маршрут наилучшим образом отражает природные и культурные преимущества парка «ЮжноПриморский» и края в целом. Методика проектирования может быть имплементирована на подобных туристских местностях.

1. Гусанов А.А. Управление экологическим туризмом в регионах России: дис. ... канд. эконом. наук: 08.00.05.

2. UNWTO Tourism Highlights 2018 Edition / World Tourism Organization, UNWTO, Madrid, 2018. $-20 \mathrm{p}$.

3. Бабкин А.В. Специальные виды туризма: учебное пособие. - Ростов-на-Дону: Феникс, 2008. $-252 \mathrm{c}$.

4. National Ecotourism Strategy. Front Cover. Australia. Commonwealth Dept. of Tourism. Commonwealth Department of Tourism, 1994. Ecotourism. - 68 p. 
5. Our Story. The International Ecotourism Society: [сайт]. - URL: https://ecotourism.org/ourstory/ (дата обращения: 10.04.2021).

6. Биржаков М. Б. Ведение в туризм: учебник. - Изд. 8-е, перераб. и доп. - СанктПетербург: Герда, 2006. - 512 с.

7. Яковлева И. А., Булатова В.В., Куклина С.К. Роль экологического туризма в развитии особо охраняемых природных территорий и экономики региона // Фундаментальные исследования. - 2015. - № 11 (часть 5) - С. 1058-1064.

8. Экотуризм. Принципы и виды. - Текст: электронный // Ассоциация экологического туризма: [сайт]. - URL: http://www.ecotourism-russia.ru/eshche_odna_vnutrennjaja/ podvnutrennjaja.html (дата обращения: 10.04.2021).

9. Понятие термина «экологический туризм». - Текст: электронный // Министерство культуры РФ. - 2020. - URL: https://www.mkrf.ru/documents (дата обращения: 10.04.2021).

10. Развитие экологического туризма: инициативы и партнерство бизнеса, общества и государства. - Улан-Удэ: Изд-во БНЦ СО РАН, 2013. - 164 с.

11. Стратегия развития туризма в Российской Федерации на период до 2035 года. Федеральное агентство по туризму: [сайт]. - URL: https://tourism.gov.ru/ contents/documenty/strategii/strategiya-razvitiya-turizma-v-rossiyskoy-federatsii-v-perioddo-2035-goda/ (дата обращения: 14.04.2021).

12. Особо охраняемые природные территории (ООПТ) // Правовой центр ДВА: [сайт]. URL: https://www.2m.ru/uslugi/voprosy-gradostroitelnoj-deyatelnosti/zony-s-osobymiusloviyami-ispolzovaniya-territorii/oopt (дата обращения: 18.04.2021).

13. Руководство по проектированию объектов инфраструктуры на ООПТ. - Текст: электронный // Агентство стратегических инициатив, 2020. - 272 с.

14. Липсиц И. В., Косов В. В. Инвестиционный проект: методы подготовки и анализа: учебно-справочное пособие. - Москва: Издательство БЕК, 2006. - 304 с.

15. Объекты инфраструктуры экотуризма. Деловой экологический журнал: [сайт]. URL: http://ecomagazine.ru/obekty-infrastruktury-ekoturizma.html (дата обращения: 18.04.2021).

16. Концепция проектируемого парка «Южно-Приморский».- Владивосток: Изд-во ВГУЭС, 2020.

\section{Транслитерация}

1. Gusanov A. A. Upravlenie ekologicheskim turizmom v regionah Rossii: dis. ... kand. ekonom. nauk: 08.00.05.

2. Babkin A. V. Special'nye vidy turizma: uchebnoe posobie. - Rostov-na-Donu: Feniks, 2008. - $252 \mathrm{~s}$.

3. Birzhakov M. B. Vedenie v turizm: uchebnik. - Izd. 8-e, pererab. i dop. - Sankt-Peterburg: Gerda, 2006. - 512 s.

4. Yakovleva I. A., Bulatova V.V., Kuklina S.K. Rol' ekologicheskogo turizma v razvitii osobo ohranyaemyh prirodnyh territorij i ekonomiki regiona // Fundamental'nye issledovaniya. 2015. - № 11 (chast' 5) - S. 1058-1064.

5. Ekoturizm. Principy i vidy. - Tekst: elektronnyj // Associaciya ekologicheskogo turizma: [sajt]. - URL: http://www.ecotourism-russia.ru/eshche_odna_vnutrennjaja/ podvnutrennjaja.html (data obrashcheniya: 10.04.2021).

6. Ponyatie termina «ekologicheskij turizm». - Tekst: elektronnyj // Ministerstvo kul'tury RF. 2020. - URL: https://www.mkrf.ru/documents (data obrashcheniya: 10.04.2021).

7. Razvitie ekologicheskogo turizma: iniciativy i partnerstvo biznesa, obshchestva i gosudarstva. - Ulan-Ude: Izd-vo BNC SO RAN, 2013. - 164 s. 
8. Strategiya razvitiya turizma v Rossijskoj Federacii na period do 2035 goda. Federal'noe agentstvo po turizmu: [sajt]. - URL: https://tourism.gov.ru/ contents/documenty/strategii/strategiya-razvitiya-turizma-v-rossiyskoy-federatsii-v-period-do2035-goda/ (data obrashcheniya: 14.04.2021).

9. Osobo ohranyaemye prirodnye territorii (OOPT) // Pravovoj centr DVA: [sajt]. - URL: https://www.2m.ru/uslugi/voprosy-gradostroitelnoj-deyatelnosti/zony-s-osobymiusloviyami-ispolzovaniya-territorii/oopt (data obrashcheniya: 18.04.2021).

10. Rukovodstvo po proektirovaniyu ob"ektov infrastruktury na OOPT. - Tekst: elektronnyj // Agentstvo strategicheskih iniciativ, 2020. - 272 s.

11. Lipsic I. V., Kosov V. V. Investicionnyj proekt: metody podgotovki i analiza: uchebnospravochnoe posobie. - Moskva: Izdatel'stvo BEK, 2006. - 304 s.

12. Ob"ekty infrastruktury ekoturizma. Delovoj ekologicheskij zhurnal: [sajt]. - URL: http://ecomagazine.ru/obekty-infrastruktury-ekoturizma.html (data obrashcheniya: 18.04.2021).

13. Koncepciya proektiruemogo parka «Yuzhno-Primorskij». - Vladivostok: Izd-vo VGUES, 2020.

(C) В.Г. Ден, 2021

(C) А.В. Суходоева, 2021

Для цитирования: Ден В.Г., Суходоева А.В. Основы проектирования туристских местностей в аспекте развития экологического туризма (на примере обустройства туристского маршрута «Гора Ливадийская» в Приморском крае) // Территория новых возможностей. Вестник Владивостокского государственного университета экономики и сервиса. - 2021. - Т. 13, № 4. - С. 72-84.

For citation: Den V.G., Suhodoeva A. V. Fundamentals for designing tourist locations in the aspect of development of ecological tourism (on the example of the arrangement of the turitian route of mountain Livadiyskaya in Primorsky krai), The Territory of New Opportunities. The Herald of Vladivostok State University of Economics and Service, 2021, Vol. 13, № 4, pp. 72-84.

DOI https://doi.org/10.24866/VVSU/2073-3984/2021-4/072-084

$\begin{array}{lll}\text { Дата поступления: } & \text { Одобрена после рецензирования: } & \text { Принята к публикации: } \\ \text { 11.11.2021 } & 12.11 .2021 & 15.11 .2021\end{array}$

